\title{
Clostridium difficile Toxic Megacolon following splenectomy
}

Maj DP Edwards

FRCSEd, RAMC*

Surgical Registrar

MA Saleemi

FRCS**

SHO Surgery

C Grundy

FRCPath

Consultant Microbiologist

\section{EM Chisholm \\ ChM,FRCS \\ Consultant Surgeon}

St Peter's Hospital, Chertsey, Surrey, KT16 OPZ

SUMMARY: A case of toxic megacolon following splenectomy for lymphoma is presented. The aetiology Clostridial difficile infection is reviewed and the hazards of perioperative prohylactic antibiotics are discussed.

\section{Case Report}

A sixty five-year-old woman, with a diagnosis of nonHodgkin's lymphoma, was referred to surgical outpatients for consideration of splenectomy. She was suffering abdominal pain and had pancytopenia, resistant to medical and oncological treatment. Staging confirmed massive splenomegaly with little extra-splenic disease. She had been diagnosed as having non Hodgkin's lymphoma 7 years earlier and had been treated with both chemotherapy and radiotherapy. Splenectomy was performed, histology confirming a lymphomatous spleen weighing $3.17 \mathrm{~kg}$. Preoperative pneumococcal, meningoccal and Haemophilus influenza vaccinations had been given, and perioperative antibiotic prophylaxis comprised ampicillin $1 \mathrm{~g}$ intravenously, followed by oral penicillin $500 \mathrm{mg}$ twice daily.

Three days postoperatively, the patient developed diarrhoea and pyrexia. Urine and blood cultures showed no bacterial growth. Chest radiograph and abdominal ultrasound failed to identify a cause for her illness. Intravenous gentamicin and high dose benzyl penicillin were commenced, without clinical improvement. Three days later, stool testing confirmed the presence of Clostridium difficile toxin, so $125 \mathrm{mg}$ oral vancomycin was given four times daily, the other antibiotics being stopped. Five days later the patient was still pyrexial, and more unwell, with progressive abdominal distension both clinically and radiologically. A diagnosis of pseudomembranous colitis complicated by toxic megacolon was made and emergency colectomy performed. The patient subsequently made an unevenfut postoperative recovery, and was discharged home fourtgene days after colectomy.

\section{Discussion}

Clostridium difficile infection is increasing in incidenco (1). The antibiotics frequently associated with Clostridium difficile infection include the cephalosporins, ampicilling amoxycillin and clindamycin (2). The most commol $\overrightarrow{5}$ presentation is diarrhoea. More severe infections may present as antibiotic associated colitis and pseudomembranous colitis. Toxic megacolon is a rare. complication of Clostridium difficile infection. Ing immunocompetent patients, toxic megacolon can occur as complication of Crohn's or ulcerative colitis, or of infectiou by Salmonella, Shigella, Campylobacter jejuni and Yersiniक enterocolitica (3). Immunocompromised patients mase develop toxic megacolon without prior antibiotic usage, and in these patients the disease process seems to have poore prognosis, particularly in HIV infected patients (3) and patients receiving anti-neoplastic chemotherapy $(4,5)$ 을 Association between lymphoma and Clostridium difficile infection is recognised (6) but to our knowledge there have been no cases reporting an association between clostridia toxic megacolon and splenectomy for lymphoma. The patient reported was immunocompromised by her having received chemotherapy, by her lymphoma and because of the splenectomy. Furthermore, she was required to receive antibiotics as part of a post-splenectomy prophylactic regimen. 
This case describes an unusual complication of splenectomy, but we suggest that if perioperative prophylactic antibiotics are given for elective splenectomy in cancer patients, clinicians should be aware of the risk of subsequent Clostridium difficile infection. A broadspectrum antibiotic seems more likely to lead to this complication. Patients undergoing total splenectomy are obviously at higher risk of postoperative attack from capsulate bacteria such as pneumococcus and long-term antibiotic prophylaxis rightly has been advised for these patients. Conversely, Clostridium difficile infection can follow a single dose of antibiotic. There is no evidence that prolonging prophylaxis past the day of operation decreases the postoperative wound infection rate in general surgery. Minimising the duration of antibiotic should also decrease the risk of Clostridium difficile infection. Our hospital's antibiotic guidelines on general surgical prophylaxis state that 1 to 3 doses of antibiotic are sufficient, starting immediately pre-operatively. Later than this is useless, longer than this is pointless.

\section{REFERENCES}

1. WILcoX MH. Clostridium difficile infection. Surg Infect 1995; 7: 74-78.

2. Committee on safety of medicines. Antibiotic associated colitis. Curr Probl Pharmacovigilance 1994; 20: 7-8.

3. Beaugerie L, NGo Y, Goujard F, et al. Etiology and management of toxic megacolon in patients with human immunodeficiency virus infection. Gastroenterology 1994; 107: 858-863.

4. Velanovich V, LaPorta AJ, Garrett WL, Richards TB, CORNETT PA. Pseudomembranous colitis leading to toxic megacolon associated with antineoplastic chemotherapy. Dis Colon Rectum 1992; 35: 369-372.

5. GRuNDFEST-BRoniatowsKi S, Quader M, ALEXANDER F, WALSH RM, LAVERY I, MILSOM J. Clostridium difficile colitis in the critically ill. Dis Colon Rectum 1996; 39: 619-623.

6. Schuller I, SaHa V, Lin L, Kingston J, Eden T, TABAQCHALI S. Investigation and management of Clostridium difficile colonisation in a paediatric oncology unit. Arch Dis Child 1995; 72: 219-222. 